\title{
MATERIAL BALANCE EQUATION OF OVERMATURE ORGANIC-RICH GAS SHALE
}

\author{
YANG, $\mathrm{Y}^{1^{*}}-\mathrm{YAN} \mathrm{P}^{2}-\mathrm{ZHOU}, \mathrm{W} .^{2}-\mathrm{OU}, \mathrm{J} . \mathrm{Q} .{ }^{3}-\mathrm{WU}, \mathrm{X}{ }^{4}$ \\ ${ }^{1}$ State Key Laboratory of Oil and Gas Reservoir Geology and Exploitation, Chengdu University \\ of Technology, Chengdu 610059, China \\ ${ }^{2}$ College of Energy, Chengdu University of Technology, Chengdu 610059, China \\ ${ }^{3}$ Central Sichuan Oil and Gasfield Research Institute, Petrochina Southwest Oil \& Gasfield \\ Company, Suinning 629000, China \\ ${ }^{4}$ China United Coalbed Methane Corporation Ltd, Beijing 100011, China \\ *Corresponding author \\ e-mail: yangyu@cdut.cn
}

(Received $15^{\text {th }}$ Jul 2017; accepted $2^{\text {nd }}$ Nov 2017)

\begin{abstract}
Gas shale was treated as a quintuple porosity system. When the source rock matures, a portion of kerogen or bitumen will be transformed into hydrocarbon, and move to displace the water out from inorganic matrix. When the kerogen is recrystallized to graphite, there will be less dissolved gas left in solid kerogen, which was assumed to be substantial in immature source rock. A series of resistivity tests showed the resistivity of shale decreases with higher vitrinite reflectance value, and proved the graphite do exist in overmature shale. With the role of natural fracture in shale analyzed, the water and hydrocarbon stored in overmature shale was summarized, and the overmature organic-rich gas shale should be treated as two porosity system. To find out which kind of pore may accommodate most of the free gas, a generalized material balance equation was presented, and the volume change with pressure drop in organic matrix and inorganic matrix can be calculated simultaneously. The field case herein proved that new material balance equation can be applied to calculate original free gas and adsorbed gas in shale or sandstone, and it was suggested that while in overmature gas shale there is free gas in inorganic pore, free gas in organic pore and adsorbed gas in kerogen, most of the free gas is in the organic pores.
\end{abstract}

Keywords: shale gas, kerogen, inorganic matrix, lamination, gas in place

\section{Introduction}

It is well accepted that gas shale is an important unconventional resource which can be viewed as a quintuple porosity system. Because hydrocarbon is stored as free gas in pore and fracture, adsorbed gas in kerogen, and dissolved gas in bitumen or kerogen. a general linear equation was created accordingly (Singh, 2013; Hejazi et al., 2017). When taking into account the organic pore and natural fracture in shale, a material balance equation was proposed for dual porosity gas shale (Zhang et al., 2013; Hashemi, 2017). A similar material balance equation was created, in which the gas stored in natural fracture can be essential (Duarte et al., 2014; Radan et al., 2017). A material balance equation was also constructed for gas condensate instead of dry gas in shale reservoir (Orozco and Aguilera, 2015). However, it is found in many basins that if the kerogen is overmature, the carbon in kerogen is recrystallizing to the mineral graphite, and the organic pore is like the coking observed in retorting of coals. Being unlike to a quintuple porosity system, the gas shale with overmature kerogen has a different distribution of gas and water, and the original material balance equation for quintuple porosity system cannot be applied without change (Ebrahimi et al., 2017). So, 
it is important to improve the conventional material balance equation for overmature shale gas reservoir.

It is also found in many basins that thin laminated layers of sandstone are imbedded in organic-rich shale. These laminated sandstone layers may be of siliceous or carbonaceous mineralogy, and have conventional porosity (Gao et al., 2017). Because the sandstone layers are interconnected with the organic-rich shale adjacent to it, it should be taken as an inseparable part in shale gas reservoirs. Herein the special property of overmature kerogen is analyzed at first, then a general material balance equation for organic-rich shale with thin laminated layers of sandstone is established, therefore original gas in organic matrix and inorganic matrix can be calculated simultaneously (Vazdani et al., 2017).

\section{Materials and methods}

The gas storage in overmature shale will be discussed in the following sections. Nomenclature is included in Appendix section.

\section{Carbonification of kerogen in overmature shale}

When the source rock is in the overmature stage, the carbon in the kerogen or bitumen was assumed to be in the process of recrystallizing to graphite, which is named as overmature shale. The amount of graphite is hard to measure precisely with X-Ray Diffraction or Scanning Electron Microscope. The electrical resistivity of graphite measured under normal temperature being from $8 \times 10^{-6} \Omega \cdot m$ to $13 \times 10^{-6} \Omega \cdot m$, it is possible to measure the amount of graphite indirectly by measuring resistivity. If there is abundant amount of graphite in shale when vitrinite reflectance is greater than $3 \%$, the rock resistivity may be much lower than that with lower thermal maturity (Passey et al., 2010; Xiao et al., 2017).

Resistivity of shale plugs with different vitrinite reflectance, or Ro, have been measured to prove whether the carbon in kerogen has been recrystallized to graphite. Because the electrically conductive material in gas shale consists of clay-bond water, capillary bond water, free water and graphite, it is useful to remove the water before test as much as possible. The shale plugs were dried to constant weight in a humidity oven, and maintained at the $45 \%$ humidity and $60{ }^{\circ} \mathrm{C}$ temperature until the weight was stable. The resistivity in Fig. 1 showed that the core plugs with vitrinite reflectance Ro greater than $2 \%$ have lower resistivity, which indicated the graphite was available in overmature shale.

Some may argue that the pyrite is also a conductive mineral commonly present in organic-rich shale, and may reduce the resistivity. The amount of pyrite is hard to measure precisely with X-Ray Diffraction or Scanning Electron Microscope. Because the grain density of pyrite is about $5.0 \mathrm{~g} / \mathrm{cc}$ compared with that of $2.6 \mathrm{~g} / \mathrm{cc}$ for quartz, even if the weight fraction of pyrite scaled to total weight is $5 \%$, the volume ratio of pyrite should be as low as $2.5 \%$, and can be negligible.

Similar to the wet clay or non-connected vug, pyrite framboids can be considered as a separate phase in conductivity model, and the contribution is controlled by their volume fraction (Hassan and Ismail, 2017; Radmanfar et al., 2017; Yang et al., 2017). When analyzing the connectivity equation in porous media, a complex conductivity model was introduced which can be used for the shale with pyrite (Montaron, 2007) (Eq. 1). 


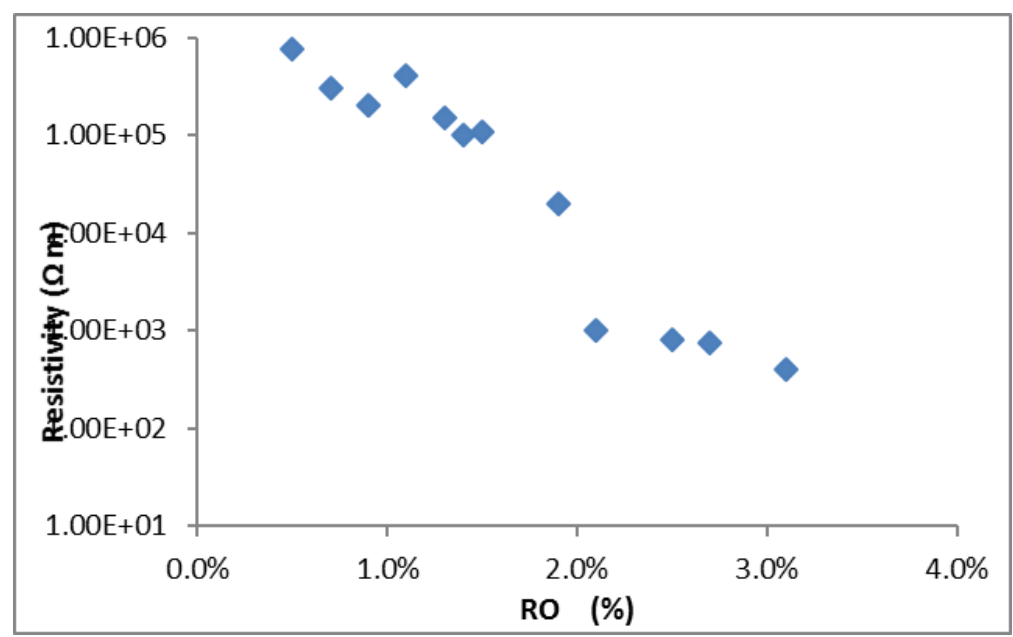

Figure 1. Resistivity of dry shale samples with different vitrinite reflectance in Xu jiahe shale and Zhenjing shale

$$
\sigma^{1 / 2}=\sigma_{c w}^{1 / 2} X_{c w}+\sigma_{w}^{1 / 2} X_{w}+\sigma_{\text {graphite }}^{1 / 2} X_{\text {graphite }}+\sigma_{\text {pyrtie }}^{1 / 2} X_{\text {pyrite }}
$$

The fact that the volume ratio of pyrite $X_{\text {pyrite }}$ is much smaller than other conductive components makes the contribution of pyrite conductivity negligible in shale. It also proved that the lower resistivity of overmature shale indicated the significant amount of graphite, and the kerogen cannot hold any dissolved gas.

\section{Gas storage in shale with different maturity}

As shown in Fig. 2, all of the pore space in immature shale is full of water initially. A portion of the kerogen will be transformed to hydrocarbon when the kerogen matures, and the hydrocarbon will move to displace some of the water out from the connected inorganic pore (Passey et al., 1990). The displacement process will continue until the capillary pressure balances with the displacement pressure. In overmature shale, there is even less water left in the inorganic pore.

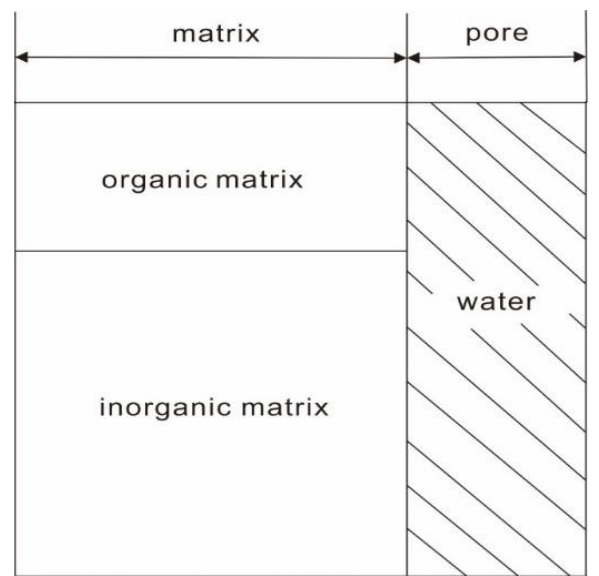

a

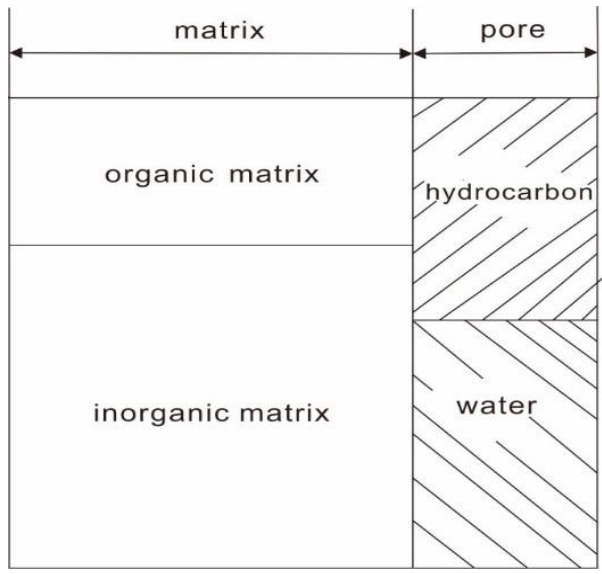

$\mathrm{b}$

Figure 2. a) Immature shale rock. b) Mature shale rock 
It was found that in Antrim shale gas of Michigan Basin, the vitrinite reflectance being $0.4 \sim 0.6 \%$, the immature shale is initially water saturated, and the water must be drained to allow gas to desorb from the matrix before production (Jenkins and Boyer, 2008). In Barnett shale gas of Fort Worth Basin, the vitrinite reflectance being $1.0 \sim 2.1 \%$, the majority of the gas in pore space is free gas, and there is little initial water production.

The storage mechanisms in shale reservoirs were concluded, and the gas shale was viewed as a quintuple porosity system: free gas in inorganic pore, free gas in organic pore, free gas in fracture, adsorbed gas in kerogen, and dissolved gas in the kerogen or bitumen (Orozco and Aguilera, 2015). Given the similarity between kerogen and bitumen underground, methane dissolved in solid kerogen underground is the same as in bitumen (Swami et al., 2013). However, when the gas shale is in the overmature stage, vitrinite reflectance being greater than $2 \%$, and the carbon in the kerogen or bitumen being recrystallized to graphite, there is little dissolved gas left in kerogen or bitumen, and the dissolved gas in solid kerogen is negligible.

\section{Role of nature fractures in shale}

Natural fractures can be sometimes observed in shale reservoirs. After analyzing the testing data of three major shale reservoirs in the US, Wang and Reed (2009) concluded that the pores in kerogen and inorganic minerals contribute the most to the total pore volume and the porosity of natural fractures is less than $0.5 \%$.

The study of Schieber (2011) showed a number of micro-fractures observed in scanning electron microscope (SEM) may be generated due to the poor preservation of shale cores. The fractures in some shale cores may be made from the stress release when they were taken from underground (Ma, 1996). Based on SEM pictures, it was also noted that the natural fractures in Barnett shale reservoir are mostly filled with secondary minerals (Kent, 2007; Gale et al., 2007). It is shown in Table 1 that the fractures are not applicable to substantial gas storage.

Table 1. Different porosity in gas shale

\begin{tabular}{|c|c|c|c|}
\hline Item & Hayneville shale & Barnett shale & Zhenjing shale \\
\hline Total organic content (TOC) & $3.5 \mathrm{wt} \%$ & $5 \mathrm{wt} \%$ & $>2 \mathrm{wt} \%$ \\
Total porosity of shale & $12 \%$ & $5 \%$ & $4 \%$ \\
Porosity in natural fractures & $<0.5 \%$ & $<0.5 \%$ & $<0.5 \%$ \\
Porosity of organics in shale & $\sim 0.7 \%$ & $\sim 1.0 \%$ & $\sim 0.8 \%$ \\
Porosity of inorganic matrix & $>10.6 \%$ & $>3.3 \%$ & $>2.7 \%$ \\
\hline
\end{tabular}

It is also shown from the observation of shale cores as shown in Fig. 3 that visible macro-fractures are not well developed in Zhenjing shale in the Ordos Basin. Because natural fractures in most of gas shales can hardly act as main storage space, the volume of natural fractures in this type of reservoir can be neglected.

\section{Gas in overmature shale}

Shale gas reservoirs are structurally more complicated than conventional reservoirs. It was found that there are thin laminated groups of sands imbedded in organic-rich shale in the Lewis shale (Grieser and Bray, 2007). It is also concluded that the $\mathrm{Xu} 5$ 
shale in Sichuan Basin is the same class of gas shale as Lewis shale which is shown in Fig. 4. At the early stage of reservoir development, primary production is through the thin sands, and black organic bulk shale feeds the sand.

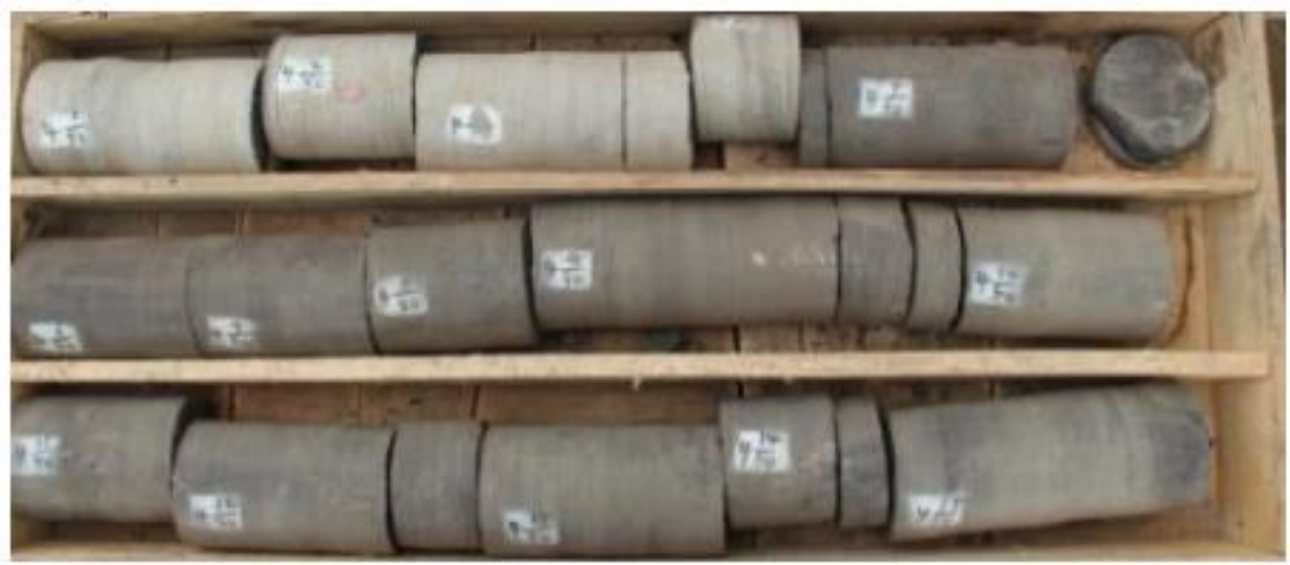

Figure 3. Core samples (824-827 m) of No. 6 Xinfu well in Zhenjing shale of Ordos Basin

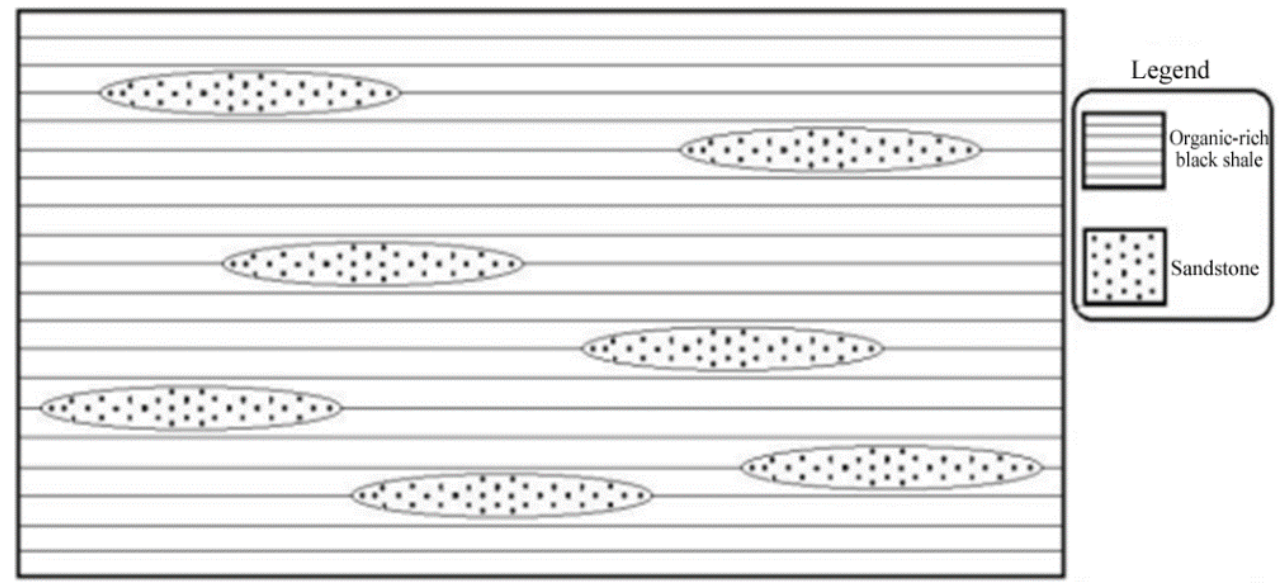

Figure 4. Laminated sands imbedded in Xu 5 shale of Sichuan Basin

Table 2 is a summary of the petro-physical properties of this type of shale gas formation, which consists of laminated layers, organic-rich shale and natural fractures. Because the laminated layers are imbedded in the organic-rich black shale, the pores and natural fractures are interconnected, and both of the sand layers and organic-rich shale should be taken as inseparable parts of shale gas reservoir. The kerogen in the organic-rich shale is also called as organic matrix. The inorganic matrix is the laminated sand layer.

The Marcellus shale and Eastern Devonian shale are quite different from Lewis shale, and they are called as black high organic content shale, with the primary production being through gas desorption from kerogen. Table 3 is a summary of the rock solid, water and hydrocarbon in this type of shale. When comparing Table 2 with Table 3, the role of laminated sandstone layers in gas shale is self evident.

However, both of the gas shales in Table 2 and Table 3 share some characteristics in common, and the components can be grouped into inorganic matrix and organic 
matrix. The inorganic matrix can be divided further into solid inorganic rock and fluid. The effective porosity is adopted in material balance calculation. According to the definition of dual water model in wireline log interpretation, clay bond water is not included in the effective porosity. Because inorganic pores are water wet, there is water and free gas in effective inorganic pore. The volume of free gas in effective inorganic pores is defined as $\mathrm{G}_{\mathrm{nk}}$.

Table 2. Components of shale with laminated sand layers

\begin{tabular}{|c|c|c|c|}
\hline Rock type & Component & Solid & Fluid \\
\hline \multirow{2}{*}{ Laminated layer } & \multirow{2}{*}{ Inorganic matrix } & \multirow{2}{*}{ Non-clay minerals } & Free gas \\
\cline { 4 - 4 } & & Clay minerals & Mobile water and capillary-bound water \\
\cline { 4 - 4 } Organic-rich shale & \multirow{2}{*}{ Organic matrix } & \multirow{2}{*}{ Kerogen } & Clay-bound water \\
\hline \multirow{2}{*}{ Natural fracture } & & & Free gas \\
\cline { 4 - 4 } & & & Mdsorbed gas \\
\cline { 4 - 4 } & & & Free gas \\
\hline
\end{tabular}

Table 3. Components of black high organic content shale

\begin{tabular}{|c|c|c|c|}
\hline Rock type & Component & Solid & Fluid \\
\hline \multirow{3}{*}{$\begin{array}{c}\text { Black high } \\
\text { organic content } \\
\text { shale }\end{array}$} & Inorganic matrix & Non-clay minerals & Free gas \\
\cline { 3 - 4 } & & Clay minerals & Mobile water and capillary-bound water \\
\cline { 2 - 4 } & Organic matrix & Kerogen & Clay bound water \\
\cline { 4 - 4 } & Natural fracture & & Free gas \\
\hline & & Adsorbed gas \\
\cline { 4 - 4 } & & & Mobile water \\
\hline
\end{tabular}

The organic matrix consists of solid kerogen and fluid. Because kerogen is non-water wet, there is only free gas and adsorbed gas in the organic pores under the original reservoir conditions. After studying the characteristics of adsorption facies by means of molecular dynamic simulation, it was found that the Langmuir adsorption model can be used for the adsorption process (Ambrose et al., 2010). The free gas in organic pores is defined as $G_{k}$, with the adsorbed gas in organic pores being defined as $G_{A}$ respectively.

If the volume of natural fractures in shale gas reservoir can be neglected, both of the gas shales in Table 2 and Table 3 can be simplified to the same volume model in Table 4.

Table 4. Simplified components of overmature gas shale

\begin{tabular}{|c|c|}
\hline \multirow[b]{2}{*}{$\begin{array}{l}\text { Fractional volume of inorganic matrix } \\
\qquad\left(V_{p m}\right)\end{array}$} & Fractional volume of solid inorganic matrix $\left(V_{s m}\right)$ \\
\hline & $\begin{array}{l}\text { Fractional volume of effective inorganic pore }\left(V_{p m} \phi_{p m}\right) \text {, in which } \\
\text { there is capillary bound water and free gas }\end{array}$ \\
\hline \multirow{2}{*}{$\begin{array}{l}\text { Fractional volume of organic matrix } \\
\qquad\left(V_{p k}\right)\end{array}$} & Fractional volume of Solid Kerogen $\left(V_{s k}\right)$ \\
\hline & $\begin{array}{l}\text { Fractional volume of organic pore }\left(V_{p k} \phi_{p k}\right) \text {, in which there is } \\
\text { adsorbed gas and free gas }\end{array}$ \\
\hline
\end{tabular}


The relationship between each part is (Eq. 2):

$$
V_{p m}+V_{p k}=1
$$

where:

$$
\begin{aligned}
& V_{p m}=V_{p m} \phi_{p m}+V_{s m}=V_{p m} \phi_{p m}+V_{p m}\left(1-\phi_{p m}\right) \\
& V_{p k}=V_{p k} \phi_{p k}+V_{s k}=V_{p k} \phi_{p k}+V_{p k}\left(1-\phi_{p k}\right) \\
& V_{p m} \phi_{p m}+V_{p k} \phi_{p k}=\phi_{T}
\end{aligned}
$$

\section{Generalized material balance equation}

Supposing the gas is stored in the organic pores, a material balance equation of coalbed methane and shale gas reservoirs was proposed (King, 1990). However, this model can not be applicable to the unconventional gas reservoirs where the pores contained in both organic matrix and inorganic matrix are substantial.

The following assumptions are made for overmature shale on the basis of the geologic characteristics discussed above.

(1) The pores of gas shale consist of inorganic pores and organic pores, which communicate with each other. This is quite true for the organic-rich shale with laminated sandstone layers.

(2) The thickness of adsorbed gas in kerogen is negligible. When the pressure drops below the critical desorption pressure, the adsorbed gas desorbs and leads to deformation of kerogen in the same way as coal.

(3) The gas dissolved in the water and kerogen is neglected.

(4) Inorganic matrix being water-wet, there may be mobile water, capillary bound water and free gas in the effective inorganic pores. In overmature shale gas reservoir, because there is little mobile water in the inorganic pores, the volume of mobile water is negligible, and only the capillary bound water is considered.

(5) Kerogen being non-water wet, there is not any water in the organic pores under the original reservoir conditions.

(6) Natural fractures only act as pathways for flow instead of storage space, so the volume of fractures is neglected.

(7) The difficulty for fracturing fluid to flow back after stimulation makes large amount of slick water remained in gas shale. The fracturing fluid left in gas shale is taken as injected water.

(8) No water influx from aquifer is considered.

(9) The reservoir temperature is constant in the process of reservoir production.

Based on the volume model in Table 4, the free gas in the inorganic matrix and the organic matrix are defined as $G_{n k}$ and $G_{k}$ respectively. Eq. 3 is the expression for total free gas in place:

$$
G=G_{n k}+G_{k}
$$


According to the principle of underground volume conservation, the material balance equation is generally expressed as:

free gas initially in place at $\mathrm{Pi}=$ pore volume occupied by free gas at $\mathrm{P}+$ change in inorganic pore + change in organic pore + desorbed gas + injected fracturing fluid produced water.

$$
\begin{aligned}
& G B_{g i}=\left(G-G_{p}\right) B_{g}+\Delta V_{n k}+\Delta V_{k}+\Delta V_{d}+W_{i}-W_{p} B_{w} \\
& \text { or : } G_{p} B_{g}+W_{p} B_{w}=G\left(B_{g}-B_{g i}\right)+\Delta V_{n k}+\Delta V_{k}+\Delta V_{d}+W_{i}
\end{aligned}
$$

It is shown in Eq. 4 that the produced gas results from the expansion of free gas and the desorption of adsorbed gas.

\section{The total volume change in the effective pores of inorganic matrix $\left(\Delta V_{n k}\right)$}

When the reservoir pressure drops to $p$, the total volume variation of water and pores in the effective pores of inorganic matrix $\left(\Delta V_{n k}\right)$ is the sum of the elastic expansion of water $\left(\Delta V_{e p n k w}\right)$ and the elastic variation of effective pores $\left(\Delta V_{\text {epnkf }}\right)$.

(1) The effect of water expansion in inorganic matrix (Eq. 5)

$$
\Delta V_{e p n k w}=\frac{G_{n k} B_{g i}}{1-S_{n k w i}} S_{n k w i}\left(e^{\int^{p} C_{w} d p}-1\right)
$$

(2) The effect of compressibility in inorganic matrix (Eq. 6)

$$
\Delta V_{e p n k f}=\frac{G_{n k} B_{g i}}{1-S_{n k w i}}\left(1-e^{-\int_{p}^{p_{i}} C_{n k} d p}\right)
$$

When Eqs. 5 and 6 are added together, the total effect of formation and the capillary bound water compressibility is $(E q .7)$

$$
\Delta V_{n k}=\Delta V_{e p n k f}+\Delta V_{e p n k w}=\frac{G_{n k} B_{g i}}{1-S_{n k w i}}\left[\left(1-e^{-\int_{p}^{p_{i}} C_{n k} d p}\right)+S_{n k w i}\left(e^{\int_{p}^{p} C_{w} d p}-1\right)\right]
$$

The compressibility of water $\left(C_{w}\right)$ and the compressibility $\left(C_{n k}\right)$ can be taken as constant sometimes. If $\mathrm{e}^{\mathrm{x}} \approx 1+\mathrm{x}, E q .7$ can be simplified as the common form as that of Moghadam et al. (2011) (Eq. 8):

$$
\Delta V_{n k}=\Delta V_{e p n k w}+\Delta V_{e p n k f}=\frac{G_{n k} B_{g i}}{1-S_{n k w i}}\left(C_{w} S_{n k w i}+C_{n k}\right)\left(p_{i}-p\right)
$$

\section{The volume change in organic matrix $\left(\Delta V_{k}\right)$}

Kerogen is non-water wet, so there is no water in the organic pores under the initial reservoir conditions. In the process of production, natural gas is desorbed when the pore 
pressure decreasing. In the overmature kerogen, the volume change of kerogen is similar to that of coal. According to the solid deformation theory, the Palmer and Mansoori (1998) model can describe the effects of compression and matrix shrinkage (Eq. 9).

$$
\frac{\phi_{p k}^{\prime}}{\phi_{p k}}=1+\frac{C_{m}}{\phi_{p k}}\left(p-p_{i}\right)+\frac{\varepsilon_{l}}{\phi_{p k}}\left(\frac{K}{M}-1\right)\left(\frac{p}{p_{L}+p}-\frac{p_{i}}{p_{L}+p_{i}}\right)
$$

where (Eq. 10):

$$
C_{m}=\frac{1}{M}-\left(\frac{K}{M}+f-1\right) \gamma
$$

$\frac{K}{M}$ in Eqs. 9 and 10 is function of Poisson's ratio (v), and it is expressed as (Eq. 11):

$$
\frac{K}{M}=\frac{1}{3}\left(\frac{1+v}{1-v}\right)
$$

Compared with the compressibility of organic pores, the compressibility of solid kerogen $(\gamma)$ is negligible, so $E q .10$ is usually simplified as (Eq. 12):

$$
C_{m}=\frac{1}{M}
$$

Eq. 9 is then simplified as $(E q .13)$ :

$$
\phi_{p k}^{\prime}-\phi_{p k}=\frac{1}{M}\left(p-p_{i}\right)+\varepsilon_{l}\left[\frac{1}{3}\left(\frac{1+v}{1-v}\right)-1\right]\left(\frac{p}{p_{L}+p}-\frac{p_{i}}{p_{L}+p_{i}}\right)
$$

The volume change of organic matrix with decreasing pore pressure is (Eq. 14):

$$
\Delta V_{k}=\frac{G_{k} B_{g i}}{\phi_{p k}}\left(\phi_{p k}-\phi_{p k}^{\prime}\right)=\frac{-G_{k} B_{g i}}{\phi_{p k}}\left\{\frac{1}{M}\left(p-p_{i}\right)+\varepsilon_{l}\left[\frac{1}{3}\left(\frac{1+v}{1-v}\right)-1\right]\left(\frac{p}{p_{L}+p}-\frac{p_{i}}{p_{L}+p_{i}}\right)\right\}
$$

\section{The desorbed volume of adsorbed gas $\left(\Delta V_{d}\right)$}

The isothermal adsorption and desorption equation of shale gas is expressed by Langmuir equation (Eq. 15):

$$
V=\frac{V_{L} p}{p_{L}+p}
$$

When the reservoir pressure is $p$, the volume of adsorbed gas is added to the free gas (Eq. 16): 


$$
\Delta V_{d}=\frac{G_{k} B_{g i}}{\phi_{p k}} \rho_{p k} B_{g}\left(\frac{V_{L} p_{i}}{p_{L}+p_{i}}-\frac{V_{L} p}{p_{L}+p}\right)
$$

\section{The expression of material balance equation}

Eqs. 3, 8, 14 and 16 are substituted into Eq. 4, and the material balance equation for the process of reservoir development is as follows ( $E q .17)$ :

$$
\begin{aligned}
& G_{p} B_{g}+W_{p} B_{w}-W_{i}=G_{n k}\left[\left(B_{g}-B_{g i}\right)+\frac{B_{g i}}{1-S_{n k w i}}\left(C_{w} S_{n k w i}+C_{n k}\right)\left(p_{i}-p\right)\right]+G_{k}\left\{\left(B_{g}-B_{g i}\right)\right. \\
& \left.-\frac{B_{g i}}{\phi_{p k}}\left[\frac{1}{M}\left(p-p_{i}\right)+\varepsilon_{l}\left(\frac{1}{3} \cdot \frac{1+v}{1-v}-1\right)\left(\frac{p}{p_{L}+p}-\frac{p_{i}}{p_{L}+p_{i}}\right)\right]+\frac{B_{g i}}{\phi_{p k}} \rho_{p k} B_{g}\left(\frac{V_{L} p_{i}}{p_{L}+p_{i}}-\frac{V_{L} p}{p_{L}+p}\right)\right\}
\end{aligned}
$$

Herein new parameters $Y, X$ and $E$ are defined as (Eqs. 18, 19 and 20):

$$
\begin{gathered}
Y=G_{p} B_{g}+W_{p} B_{w}-W_{i} \\
X=B_{g}-B_{g i}-\frac{B_{g i}}{\phi_{p k}}\left[\frac{1}{M}\left(p-p_{i}\right)+\varepsilon_{l}\left(\frac{1}{3} \cdot \frac{1+v}{1-v}-1\right)\left(\frac{p}{p_{L}+p}-\frac{p_{i}}{p_{L}+p_{i}}\right)\right]+\frac{B_{g i}}{\phi_{p k}} \rho_{p k} B_{g}\left(\frac{V_{L} p_{i}}{p_{L}+p_{i}}-\frac{V_{L} p}{p_{L}+p}\right) \\
E=\left(B_{g}-B_{g i}\right)+\frac{B_{g i}}{1-S_{n k w i}}\left(C_{w} S_{n k w i}+C_{n k}\right)\left(p_{i}-p\right)
\end{gathered}
$$

Eq. 17 is expressed as (Eq. 21):

$$
\frac{Y}{E}=G_{n k}+G_{k} \frac{X}{E}
$$

Eq. 21 is a linear equation with slope of $G_{k}$ and intercept of $G_{n k}$. Based on actual production data and gas reservoir pressure data, the relationship between $\frac{Y}{E}$ and $\frac{X}{E}$ is plotted. Then, $G_{k}$ and $G_{n k}$ are calculated by means of linear fitting.

The calculation equation of adsorbed gas reserves is as follows (Eq. 22):

$$
G_{A}=G_{k} \frac{B_{g i}}{\phi_{p k}} \rho_{p k}\left(\frac{V_{L} p_{i}}{p_{L}+p_{i}}\right)
$$

\section{Results}

The material balance equation was applied to a pilot production block of a shale gas reservoir in Xu 5 shale in Sichuan Basin of China. During the production, only gas was produced. The remaining fluid of $5100 \mathrm{~m}^{3}$ did not flow back after stimulation. The gravity of natural gas was 0.65 . Other basic reservoir parameters and production data are shown in Tables 5 and 6 respectively. 
Table 5. Parameters of shale gas reservoir

\begin{tabular}{|c|c|c|c|}
\hline Parameter & Value & Parameter & Value \\
\hline $\begin{array}{c}\text { Initial reservoir pressure } \\
\left(P_{i}\right)\end{array}$ & $27.09 \mathrm{MPa}$ & Langmuir volume $\left(V_{L}\right)$ & $42.22 \mathrm{~m}^{3} / \mathrm{t}$ \\
\hline $\begin{array}{c}\text { Initial gas volume factor } \\
\left(B_{g i}\right)\end{array}$ & $3.8 \times 10^{-3} \mathrm{~m}^{3} / \mathrm{m}^{3}$ & Porosity of kerogen $\left(\phi_{\mathrm{pk}}\right)$ & 0.05 \\
\hline $\begin{array}{c}\text { Compressibility of } \\
\text { inorganic matrix }\left(C_{n k}\right)\end{array}$ & $0.00125 \mathrm{MPa}^{-1}$ & Langmuir pressure $\left(p_{L}\right)$ & $25.5 \mathrm{MPa}$ \\
\hline $\begin{array}{c}\text { Compressibility of water } \\
\left(C_{w}\right)\end{array}$ & $0.000435 \mathrm{MPa}^{-1}$ & $\begin{array}{c}\text { Parameters of Langmuir } \\
\text { curve }\left(\varepsilon_{l}\right)\end{array}$ & 0.0128 \\
\hline $\begin{array}{c}\text { Water saturation in } \\
\text { inorganic matrix }\left(S_{n k w i}\right)\end{array}$ & $2.0 \mathrm{t} / \mathrm{m}^{3}$ & $\begin{array}{c}\text { Axial constraint modulus } \\
(M)\end{array}$ & $6136 \mathrm{MPa}$ \\
\hline $\begin{array}{c}\text { Density of kerogen }\left(\rho_{p k}\right) \\
\text { Derog ratio of } \\
\text { kerogen }(v)\end{array}$ & 0.23 \\
\hline
\end{tabular}

Table 6. Production history

\begin{tabular}{|c|c|c|}
\hline Pressure (p/MPa) & $\begin{array}{c}\text { Cumulative gas production } \\
\left(\mathbf{G}_{\mathbf{p}} / \mathbf{m}^{\mathbf{3}}\right)\end{array}$ & Gas volume factor $\left(\mathbf{B}_{\mathbf{g}} / \mathbf{m}^{\mathbf{3}} / \mathbf{m}^{\mathbf{3}}\right)$ \\
\hline 25.12 & 4710000 & 0.004 \\
23.21 & 6085000 & 0.0044 \\
20.09 & 7721000 & 0.005 \\
15.12 & 11002000 & 0.0065 \\
9.04 & 15530000 & 0.0115 \\
\hline
\end{tabular}

Parameters $Y, X$ and $E$ are calculated with Eqs. 18, 19 and 20 are shown in Table 7. The relation of $\frac{Y}{E}$ vs. $\frac{X}{E}$ is plotted as Fig. 5 shown. After regression with linear function, the initial total free gas at standard condition is $0.2901 \times 10^{8} \mathrm{~m}^{3}$, free gas in kerogen being $0.2223 \times 10^{8} \mathrm{~m}^{3}$ and free gas in inorganic matrix being $0.0678 \times 10^{8} \mathrm{~m}^{3}$. Based on the calculation results, the free gas in inorganic matrix is $23.37 \%$ of total free gas reserves. Based on Eq. 22, the adsorbed gas in kerogen is $0.0774 \times 10^{8} \mathrm{~m}^{3}$.

Table 7. Calculation of key parameters

\begin{tabular}{|c|c|c|c|c|c|c|}
\hline $\begin{array}{c}\text { Pressure } \\
(\mathbf{p} / \mathbf{M P a})\end{array}$ & $\begin{array}{c}\text { Total volume } \\
\text { change of } \\
\text { inorganic } \\
\text { matrix }\left(\Delta \mathbf{V}_{\mathbf{n k}}\right. \\
\left.\quad / \mathbf{m}^{\mathbf{3}}\right)\end{array}$ & $\begin{array}{c}\text { Volume } \\
\text { change of } \\
\text { pores in } \\
\text { organic } \\
\text { matrix } \\
\left(\Delta \mathbf{V}_{\mathrm{k}} / \mathbf{m}^{3}\right)\end{array}$ & $\begin{array}{c}\text { Volume of } \\
\text { adsorbed gas } \\
\left(\Delta \mathbf{V}_{d^{\prime}} / \mathbf{m}^{3}\right)\end{array}$ & $\begin{array}{l}\text { Parameter } \\
(\mathbf{Y})\end{array}$ & $\begin{array}{l}\text { Parameter } \\
\text { (X) }\end{array}$ & $\begin{array}{l}\text { Parameter } \\
\text { (E) }\end{array}$ \\
\hline 25.12 & 71.46 & 291.21 & 9067.44 & 13740 & 0.000864 & 0.000810524 \\
\hline 23.21 & 140.74 & 559.77 & 20414.88 & 21674 & 0.00134 & 0.001220704 \\
\hline 20.09 & 253.92 & 965.60 & 44717.65 & 33505 & 0.002095 & 0.001837287 \\
\hline 15.12 & 434.20 & 1510.07 & 111570.17 & 66413 & 0.003995 & 0.003363581 \\
\hline 9.04 & 654.75 & 1943.07 & 350052.54 & 173495 & 0.010356 & 0.008395546 \\
\hline
\end{tabular}


It is interesting to note that the calculated free gas in kerogen is $76.63 \%$, which agrees with the assumption that most of the free gas may be in the organic pores in the overmature organic-rich shale gas reservoirs (Passey et al., 2010).

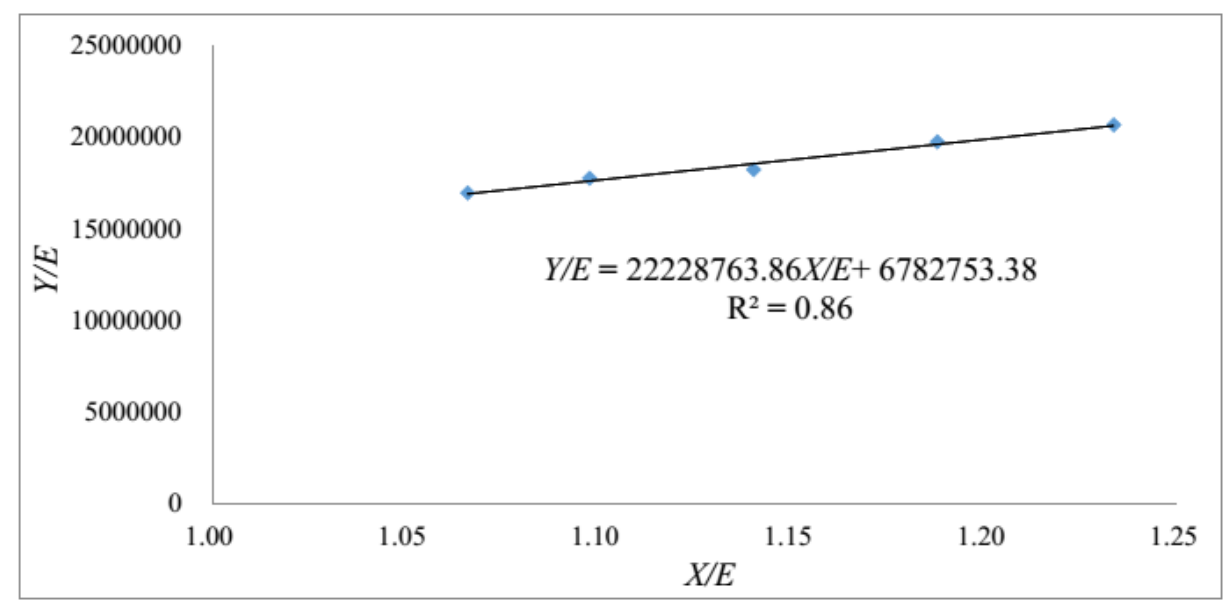

Figure 5. Y/E versus $X / E$

\section{Discussions}

The resistivity of dry shale samples with different vitrinite reflectance in $\mathrm{Xu}$ jiahe shale and Zhenjing Shale showed that if vitrinite reflectance is greater than $2 \%$, the rock resistivity is much lower than that with lower thermal maturities. It proves that there being abundant amount of solid graphite in overmature shale, and the dissolved gas in the kerogen or bitumen should be negligible.

Natural fractures in most of gas shales can hardly act as a main storage space. Therefore, the volume of natural fractures in this type of reservoir can be neglected.

In some gas shale, thin laminated layers of sandstone are imbedded in organic-rich shale, and free gas in inorganic matrix is also too important to neglect. The distinct feature of inorganic matrix and kerogen should be considered. The inorganic pores are water wet, there being water and free gas in effective inorganic pore, while Kerogen is non-water wet, there is only free gas and adsorbed gas in the organic pores.

For both thin laminated layers of sandstone imbedded in organic-rich shale and high organic content black shale, a generalized material balance equation is developed with the principle of material balance, Langmuir isothermal adsorption model and Palmer and Mansoor (1998) model. Gas in organic matrix and inorganic matrix could be calculated simultaneously, and it is showed that the majority of the free gas is in the organic pores in the overmature organic-rich shale gas reservoirs.

\section{Conclusions}

Gas shale was treated as a quintuple porosity system, but the overmature organic-rich gas shale can be simplified as two porosity system.

An advanced gas material balance equation was presented for the overmature organic-rich gas shale, and the corresponding function was also introduced the material balance equation can be plotted as a straight line. A field case showed that in overmature gas shale, most of the free gas is in the organic pores. 
Acknowledgements. The authors gratefully acknowledge the funding from the National Key Research and Development Program of China (The Chengdu University of Technology Subcontract No. 2016ZX05025002-005), which provided support for the work done here.

\section{REFERENCES}

[1] Ambrose, R. J., Hartman, R. C., Campos, M. D., Akkutlu, I. Y., Sondergeld, C. (2010): New pores-scale considerations for shale gas in place calculations. - Society of Petroleum Engineers 17: 219-229.

[2] Duarte, J. C., Viñas, E. C., Ciancaglini, M. (2014): Material balance analysis of naturally or artificially fractured shale gas reservoirs to maximize final recovery. - SPE Latin America and Caribbean Petroleum Engineering Conference, 21-23 May, Maracaibo, Venezuela. Society of Petroleum Engineers.

[3] Ebrahimi, N., Gharibreza, M., Hosseini, M., Ashraf, M. A. A. (2017): Experimental study on the impact of vegetation coverage on flow roughness coefficient and trapping of sediment. - Geology, Ecology, and Landscapes 1(3): 167-172.

[4] Gale, J. F. W., Reed, R. M, Holder, J. (2007): Natural fractures in the Barnett shale and their importance for hydraulic fracture treatments. - American Association of Petroleum Geologists 91(4): 603-622.

[5] Gao, W., Kanna, M. R. R., Suresh, E., Farahani, M. R. (2017): Calculating of degreebased topological indices of nanostructures. - Geology, Ecology, and Landscapes 1(3): 173-183.

[6] Grieser, W. V., Bray, J. M. (2007): Identification of production potential in unconventional reservoirs. - Production and Operations Symposium, 31 March-3 April, Oklahoma City, Oklahoma, U.S.A. Society of Petroleum Engineers.

[7] Hashemi, N. (2017): Recognizing the potential of sustainable use of pasture resources in south khorasan province with approch of carrying capacity. - Environment Ecosystem Science 1(2): 09-12.

[8] Hassan, M. A., Ismail, M. A. M. (2017): Literature review for the development of Dikes's breach channel mechanism caused by erosion processes during overtopping failure. Engineering Heritage Journal 1(2): 23-30.

[9] Hejazi, S.M., Lotfi, F., Fashandi, H., Alirezazadeh, A. (2017): Serishm: an eco-friendly and biodegradable flame retardant for fabrics. - Environment Ecosystem Science 1(2): 05-08.

[10] Jenkins, C. D., Boyer, C. M. II. (2008): Coalbed- and shale-gas reservoirs. - Journal of Petroleum Technology 60(2): 92-99.

[11] Kent, A. B. (2007): Barnett shale gas production, Fort Worth Basin: Issues and discussion. - American Association of Petroleum Geologists 91: 523-524.

[12] King, R. G. (1990): Material balance techniques for coal seam and Devonian shale gas reservoirs. - SPE Annual Technical Conference and Exhibition, 23-26 September, New Orleans, Louisiana. Society of Petroleum Engineers.

[13] Ma, X. (1996): Reservoir fracture property of third member of Shahejie formation in Hubuzhairegion. - Journal of Oil and Natural Gas Geology 17(1): 48-52.

[14] Moghadam, S., Jeje, O., Mattar, L. (2011): Advanced gas material balance in simplified format. - Journal of Canadian Petroleum Technology 50(1): 90-98.

[15] Montaron, B. A. (2007): A quantitative model for the effect of wettability on the conductivity of porous rocks. - SPE Middle East Oil and Gas Show and Conference, 1114 March, Manama, Bahrain. Society of Petroleum Engineers.

[16] Orozco, D., Aguilera, R. (2015): A material balance equation for stress-sensitive shale gas condensate reservoirs. - SPE Latin American and Caribbean Petroleum Engineering Conference, 18-20 November, Quito, Ecuador. Society of Petroleum Engineers. 
[17] Palmer, I., Mansoori, J. (1998): How permeability depends on stress and pore pressure in colabeds: a new model. - SPE Reservoir Evaluation \& Engineering 1(6): 539-544.

[18] Passey, Q. R., Bohacs, K., Esch, W. L., Klimentidis, R., Sinha, S. (2010): From oil-prone source rock to gas-producing shale reservoir - Geologic and petrophysical characterization of unconventional shale gas reservoirs. - International Oil and Gas Conference and Exhibition in China, 8-10 June, Beijing, China. Society of Petroleum Engineers.

[19] Passey, Q. R., Creaney, S., Kulla, J. B., Moretti, F. J., Stroud, J. D. (1990): A Practical model for organic richness from porosity and resistivity logs. - American Association of Petroleum Geologists 74(12): 1777-1794.

[20] Radan, A., Latifi, M., Moshtaghie, M., Ahmadi, M., Omidi, M. (2017): Determining the Sensitive Conservative Site in Kolah Ghazi National Park, Iran, In Order to Management Wildlife by Using GIS Software. - Environment Ecosystem Science 1(2): 13-15.

[21] Radmanfar, R., Rezayi, M., Salajegheh, S., Bafrani, V. A. (2017): Determination the most important of hse climate assessment indicators case study: hse climate assessment of combined cycle power plant staffs. - Journal CleanWAS 1(2): 23-26.

[22] Schieber, J. (2011): Shale Microfabrics and Pore Development. - an Overview with Emphasis on the Importance of Depositional Processes. - In Leckie, D. A., Barclay, J. E. (eds.) Gas Shale of the Horn River Basin. Canadian Society of Petroleum Geologists, Calgary.

[23] Singh, V. K. (2013): Overview of material balance equation (MBE) in shale gas \& nonconventional reservoir. - SPE Middle East Oil and Gas Show and Conference, 10-13 March, Manama, Bahrain. Society of Petroleum Engineers.

[24] Swami, V., Settari, A., Javadpour, F. (2013): A numerical model for multi-mechanism flow in shale gas reservoirs with application to laboratory scale testing. - EAGE Annual Conference \& Exhibition incorporating SPE Europec, 10-13 June, London, UK. Society of Petroleum Engineers.

[25] Vazdani, S., Sabzghabaei, G., Dashti, S., Cheraghi, M., Alizadeh, R., Hemmati, A. (2017): Fmea Techniques Used in Environmental Risk Assessment. - Environment Ecosystem Science 1(2): 16-18.

[26] Wang, F. P., Reed, R. M. (2009): Pore networks and fluid flow in gas shales. SPE Annual Technical Conference and Exhibition, 4-7 October, New Orleans, Louisiana. Society of Petroleum Engineers.

[27] Xiao, H., Wang, M., Sheng, S. (2017): Spatial evolution of URNCL and response of ecological security: a case study on Foshan City. - Geology, Ecology, and Landscapes 1(3): 190-196.

[28] Yang, S., Li, J., Song, Y. (2017): Application of surfactant Tween 80 to enhance Fenton oxidation of polycyclic aromatic hydrocarbons (PAHs) in soil pre-treated with Fenton reagents. - Geology, Ecology, and Landscapes 1(3): 197-204.

[29] Zhang, L. H., Chen, G., Zhao, Y. L., Zhang, H., Liu, Q. (2013): A modified material balance equation for shale gas reservoirs and a calculation method of shale gas reserves.

- Natural Gas Engineering 33: 66-70. 


\section{APPENDIX}

\section{Nomenclature}

$\sigma$ is the total conductivity of the gas shale;

$X_{c w}$ is the bulk volume fraction of claybound water;

$\sigma_{c w}$ is the conductivity of claybound water;

$X_{w}$ is the bulk volume fraction of capillary bound or free water;

$\sigma_{w}$ is the conductivity of capillary bound or free water;

$X_{\text {graphite }}$ is the bulk volume fraction of graphite;

$\sigma_{\text {graphite }}$ is the conductivity of graphite;

$X_{\text {pyrite }}$ is the bulk volume fraction of pyrite;

$\sigma_{\text {pyrite }}$ is the conductivity of pyrite;

$V_{p m}$ is the volume ratio of inorganic matrix scaled to the bulk volume of the composite system, dimensionless;

$V_{p k}$ is the volume ratio of organic matrix scaled to the bulk volume of the composite system, dimensionless;

$\phi_{p m}$ is the effective pores in inorganic matrix, dimensionless;

$V_{s m}$ is the volume ratio of inorganic solid to inorganic matrix, dimensionless;

$\phi_{p k}$ is the initial porosity in kerogen, dimensionless;

$V_{s k}$ is the volume ratio of solid kerogen to organic matrix, dimensionless;

$\phi_{T}$ is the total porosity, dimensionless;

$p_{i}$ is the initial pressure, $\mathrm{MPa}$;

$p$ is the reservoir pressure, $\mathrm{MPa}$;

$G$ is the total free gas in the reservoirs at standard condition, $\mathrm{m}^{3}$;

$G_{n k}$ is the free gas in inorganic matrix at standard condition, $\mathrm{m}^{3}$;

$G_{k}$ is the free gas reserves in organic matrix at standard condition, $\mathrm{m}^{3}$;

$G_{A}$ is the adsorbed gas in organic matrix at standard condition, $\mathrm{m}^{3}$;

$B_{g i}$ is the gas volume factor at initial reservoir pressure, $\mathrm{m}^{3} / \mathrm{m}^{3}$;

$G_{p}$ is the cumulative gas production, $\mathrm{m}^{3}$;

$B_{g}$ is the gas volume factor at the reservoir pressure $p, \mathrm{~m}^{3} / \mathrm{m}^{3}$;

$W_{p}$ is the cumulative water production, $\mathrm{m}^{3}$;

$B_{w}$ is the water volume factor at the reservoir pressure $p, \mathrm{~m}^{3} / \mathrm{m}^{3}$;

$\Delta V_{n k}$ is the total volume change of water and pores in the effective pores of inorganic matrix, $\mathrm{m}^{3}$;

$\Delta V_{k}$ is the volume change of pores in organic matrix, $\mathrm{m}^{3}$;

$\Delta V_{d}$ is the volume of adsorbed gas at the reservoir pressure of $p, \mathrm{~m}^{3}$;

$W_{i}$ is the cumulative water injection, $\mathrm{m}^{3}$;

$\Delta V_{\text {epnkw }}$ is the volume change of water in the effective pores of inorganic matrix, $\mathrm{m}^{3}$;

$\Delta V_{\text {epnkf }}$ is the volume change of effective pore in inorganic matrix, $\mathrm{m}^{3}$;

$S_{n k w i}$ is the water saturation in inorganic matrix, dimensionless;

$P_{i}$ is the original reservoir pressure, $\mathrm{MPa}$;

$p$ is the current reservoir pressure, $\mathrm{MPa}$;

$C_{w}$ is the compressibility of water, $\mathrm{MPa}^{-1}$;

$C_{n k}$ is the compressibility of inorganic matrix, $\mathrm{MPa}^{-1}$;

$\phi_{\mathrm{pk}}^{\prime}$ is the porosity of kerogen at the pressure of $p$, dimensionless; 
$C_{m}$ is the expansion factor of organic matrix, $\mathrm{MPa}^{-1}$;

$\varepsilon_{l}$ is parameters of Langmuir curve match to volumetric strain change because of matrix shrink age, dimensionless;

$K$ is bulk modulus, MPa;

$M$ is the axial constraint modulus, MPa;

$p_{L}$ is the Langmuir pressure, $\mathrm{MPa}$;

$f$ is the factor $(0-1)$, dimensionless;

$\gamma$ is the compressibility of solid kerogen, $\mathrm{MPa}^{-1}$;

$v$ is the Poisson's ratio of kerogen, dimensionless;

$V_{L}$ is the Langmuir volume, $\mathrm{m}^{3} / \mathrm{t}$;

$\rho_{p k}$ is the apparent density of kerogen, $\mathrm{t} / \mathrm{m}^{3}$; and

$V$ is the adsorbed gas at the pressure $p, \mathrm{~m}^{3} / \mathrm{t}$. 